\title{
ALEXANDER et al.
}

\section{The potential "additive" thromboembolic risk of radiotherapy}

\author{
Marliese Alexander ${ }^{1,2^{*}}$, Rebekka Sryjanen ${ }^{3}$, David Ball ${ }^{4}$, Michael MacManus ${ }^{4}$, Kate Burbury ${ }^{5}$ \\ ${ }^{1}$ Pharmacy Department Peter MacCallum Cancer Centre, 305 Grattan Street, Melbourne 3000 Australia \\ ${ }^{2}$ Sir Peter MacCallum Department of Oncology, The University of Melbourne, Parkville 3010 Australia \\ ${ }^{3}$ Faculty of Pharmacy and Pharmaceutical Sciences Monash University, 381 Royal Parade Parkville 3052 \\ Australia \\ ${ }^{4}$ Department of Radiation Oncology, Peter MacCallum Cancer Centre, 305 Grattan Street Melbourne 3000 \\ Australia, Sir Peter MacCallum Department of Oncology, The University of Melbourne, Parkville 3010 Australia \\ ${ }^{5}$ Department of Haematology, Peter MacCallum Cancer Centre, 305 Grattan Street, Melbourne 3000 Australia \\ *Correspondence: \\ Ms Marliese Alexander, Peter MacCallum Cancer Centre, 305 Grattan Street Melbourne Australia 3000. \\ Email: Marliese.Alexander@petermac.org \\ To Editor,
}

We read with interest the meta-analysis of primary prevention of thromboembolism (TE) in ambulatory lung cancer patients receiving chemotherapy recently published in APJCO (2018 Jun;14(3):210-216). This analysis confirms previously reported findings of the benefit of primary thromboprophylaxis for TE prevention during chemotherapy but with high number needed to treat warranting a more targeted approach, as currently being investigated in ongoing trials.

\section{A}

Contributions of therapeutic modality to TE risk are not the same and not well elucidated to date. In particular the potential "additive" TE risk of radiotherapy remains an important unanswered question given that radiotherapy continues to be a mainstay therapeutic modality for many tumours in both the curative and palliative setting.

The limited and and largely retrospective data (Table 1) suggests TE rates among patients with cancer receiving radiotherapy as the sole modality are lower comparatively to chemotherapy or combination chemoradiotherapy. But there is a lack of high quality prospective data truly estimating incidence and cumulative risk.

We identified only one study evaluating TE among patients receiving single modality radiotherapy. ${ }^{1}$ Other studies indiscriminately included patients receiving radiotherapy in conjunction with systemic therapies (Table $1)^{2-5}$ In a prospective registry study, $13 \%$ (1202/9284) of patients who suffered TE in the setting of active cancer received radiotherapy. ${ }^{2}$ However, nearly three quarters received concomitant therapies; $65 \%$ chemotherapy and $9 \%$ hormone therapy.

We have recently completed a prospective study (BIOTEL, biomarkers of thromboembolism in lung cancer), in which patients were longitudinally profiled to assess TE risk and incident rates (under review). This study included a small cohort of patients receiving single modality radiotherapy $(n=34)$. Despite $88 \%$ demonstrating a procoagulant thrombogenic biomarker profile (thromboelastography and fibrinogen/D-dimer studies), only one patient developed TE over 12-month follow-up period.

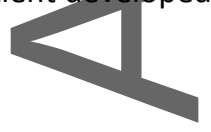

This is the author manuscript accepted for publication and has undergone full peer review but has not been through the copyediting, typesetting, pagination and proofreading process, which may lead to differences between this version and the Version of Record. Please cite this article as doi:

10.1111/ajco.13099.

This article is protected by copyright. All rights reserved. 
We also retrospectively assessed TE incidence in a larger cohort of patients with lung cancer treated with single modality radiotherapy enrolled in a local prospective cohort study. Patients received either curative or palliative intent single modality primary, mediastinal, or chest wall radiotherapy from 2012 to 2016. Enrolment was from the commencement of radiotherapy to the earliest date of death, loss to follow-up, commencement of chemotherapy or surgery, or end of study (3 months). Patients receiving concurrent chemotherapy or therapeutic anticoagulation were excluded. Among 441 patients with lung cancer, 18 (4\%) developed TE (13 venous and 5 arteriaf); median time to TE was 30 days (range 1-77). While TE incidence in this study (4\%) was similar to the small prospective BIOTEL study (3\%) and the previously described retrospective study of single modality radiotherapy $(3-6 \%)^{1}$ and lower than the $10-20 \%$ incidence reported among lung cancer patients receiving chemotherapy, findings should be confirmed in a larger prospective design.

Accordingly, as part of a recently opened phase III trial of targeted primary thromboprophylaxis (TARGET-TP), we have extended eligibility to patients receiving single modality radiotherapy (ANZCTRN12618000811202). While limited to an observation cohort only, this represents a prospective opportunity to assess longitudinal thrombogenic bjomarker profiles and correlative thrombohemorrhagic clinical outcomes for this under researched and clinically relevant treatment setting.

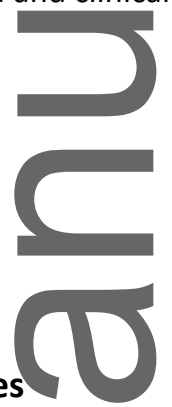

\section{References}

1. Cherkashin M, Berezina N, Vorobyov N, Pinelis E. EP-1430: Venous thromboembolism in radiation oncology: retrospective trial. Radiother Oncol. 2017;123:S763.

2. Guy J-B, Bertoletti L, Magné N, Rancoule C, Mahé I, Font C, et al. Venous thromboembolism in radiation therapy cancer patients: Findings from the RIETE registry. Crit Rev Oncol Hematol. 2017;113:83-89. 3. Ashrani AA, Gullerud RE, Petterson TM, Marks RS, Bailey KR, Heit JA. Risk factors for incident venous thromboembolism in active cancer patients: a population based case-control study. Thromb Res. 2016;139:2937.

4. LeeYG, Kim I, Lee E, et al. Risk factors and prognostic impact of venous thromboembolism in Asian patients with non-small cell lung cancer. Thromb Haemost. 2014;111:1112-1120.

5. Blom JW, Vanderschoot JP, Oostindier MJ, Osanto S, van der Meer FJ, Rosendaal FR. Incidence of venous thrombosis in a large cohort of 66,329 cancer patients: results of a record linkage study. J Thromb Haemost. 2006;4:529-535.

Table 1 - Summary of studies reporting thromboembolism among patients receiving radiotherapy

\begin{tabular}{|l|l|l|l|l|l|l|}
\hline Study & $\begin{array}{l}\text { Desig } \\
\mathbf{n}\end{array}$ & $\begin{array}{l}\text { No. } \\
\text { treated } \\
\text { with RT }\end{array}$ & $\begin{array}{l}\text { RT } \\
\text { alone }^{\text {a }}\end{array}$ & $\begin{array}{l}\text { Cancer } \\
\text { diagnosi } \\
\text { S }\end{array}$ & VTE rate & $\begin{array}{l}\text { VTE risk (95\%Cl) for } \\
\text { RT vs. no RT or other } \\
\text { TX }^{2}\end{array}$ \\
\hline Alexander 2018 & $\mathrm{P}$ & 35 & $100 \%$ & NSCLC & $3 \%$ & HR 0.14 (0.02-1.05) \\
\hline Alexander 2018 & $\mathrm{R}$ & 441 & $100 \%$ & NSCLC & $3 \%$ & NR $^{\mathrm{c}}$ \\
\hline $\begin{array}{l}\text { Cherkashin et al. } \\
(2017)^{1}\end{array}$ & $\mathrm{R}$ & 323 & $100 \%$ & Mixed & $6 \%$ brain & $\begin{array}{l}5 \% \text { increased VTE risk } \\
\text { with RT, } P=0.018\end{array}$ \\
\hline
\end{tabular}

This article is protected by copyright. All rights reserved. 


\begin{tabular}{|c|c|c|c|c|c|c|}
\hline Guy et al. $(2017)^{2}$ & $P$ & 1202 & $26 \%^{\mathrm{e}}$ & $22 \% \mathrm{LC}$ & $N R^{f}$ & RR 1.72 (1.52-1.95) \\
\hline $\begin{array}{l}\text { Ashrani et al. } \\
(2015)^{3}\end{array}$ & $\mathrm{R}$ & 54 & $N R^{g}$ & $12 \% L^{h}$ & $N R^{f}$ & OR 1.77 (1.00-3.15) \\
\hline Lee et al. & $\mathrm{R}$ & 582 & $N R^{g}$ & NSCLC & $\begin{array}{l}6 \% \text { Cur } \\
13 \% \mathrm{Pal}\end{array}$ & $\begin{array}{l}\text { Cur HR } 1.4(0.7-2.7) \\
\text { Pal HR } 3.4(2.4-5.0)\end{array}$ \\
\hline Blom et al. & $\mathrm{R}$ & 12261 & $N R^{g}$ & $14 \% L C^{h}$ & $\begin{array}{l}\text { 1\% stage I- } \\
\text { III } 1 \% \text { stage } \\
\text { IV }\end{array}$ & $\begin{array}{l}\text { Stage I-III HR } 0.8 \text { (0.6- } \\
1.0) \\
\text { Stage IV HR } 0.7 \text { (0.4- } \\
1.1)\end{array}$ \\
\hline
\end{tabular}

${ }^{a}$ Remaining cohort treated with concomitant chemotherapy; ${ }^{b}$ Hazard ratio for single modality radiotherapy versus chemoradiotherapy or chemotherapy; 'Cohort included only patients treated with radiotherapy; ${ }^{\mathrm{d}}$ Sits of radiation included abdomen, pelvis, chest, and breast; ${ }^{\mathrm{e}}$ Calculated from published data; ${ }^{\mathrm{f}}$ Cohort included only patients with VTE (registry or case control study), ${ }^{\mathrm{g}}$ Concomitant chemotherapy included but breakdown not reported; ${ }^{\mathrm{h}}$ Proportion of lung cancer patients in overall study cohort may not reflect proportion treated with radiotherapy. $\mathrm{Cl}$, confidence interval; $\mathrm{CHT}$, chemotherapy; Cur, curative intent radiotherapy; LC, lung cancer; NR, not reported; P, prospective, Pal, palliative intent radiotherapy; $\mathrm{R}$, retrospective; $\mathrm{RT}$, radiotherapy; $\mathrm{Tx}$, treatment; $\mathrm{VTE}$, venous thromboembolism.

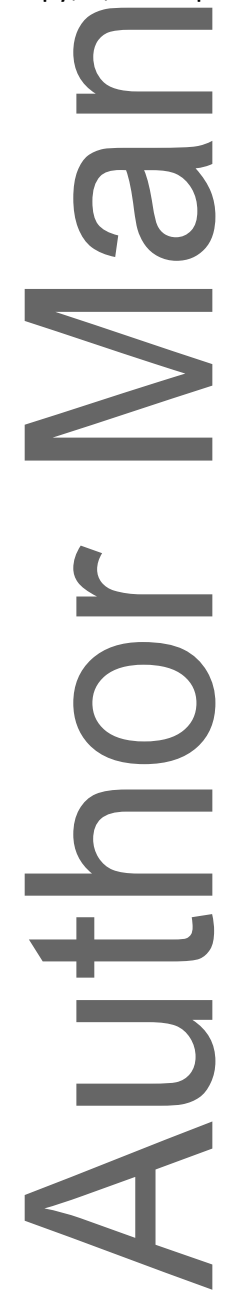




\section{University Library}

\section{- M M N E R VA A gateway to Melbourne's research publications}

Minerva Access is the Institutional Repository of The University of Melbourne

Author/s:

Alexander, M;Sryjanen, R;Ball, D;MacManus, M;Burbury, K

Title:

The potential "additive" thromboembolic risk of radiotherapy

Date:

2019-06-01

Citation:

Alexander, M., Sryjanen, R., Ball, D., MacManus, M. \& Burbury, K. (2019). The potential "additive" thromboembolic risk of radiotherapy. ASIA-PACIFIC JOURNAL OF CLINICAL ONCOLOGY, 15 (3), pp.183-184. https://doi.org/10.1111/ajco.13099.

Persistent Link:

http://hdl.handle.net/11343/284775 